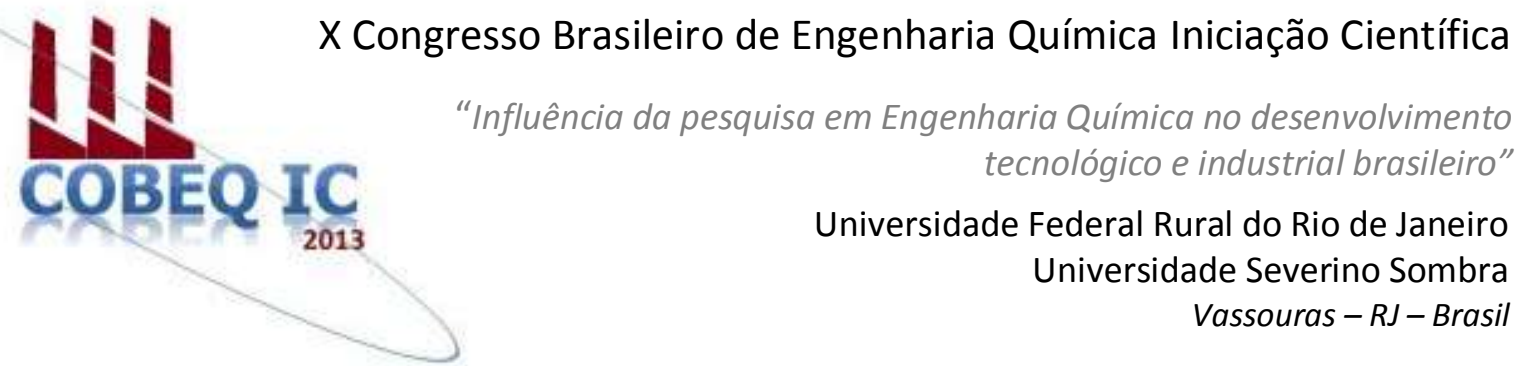

\title{
ESTUDO DO EFEITO DE CONTAMINANTE NÍQUEL NO PROCESSO DE DEGRADAÇÃO DO HIPOCLORITO DE SÓDIO
}

\author{
R. L. ALMEIDA ${ }^{1}$; B. C. R. COSTA ${ }^{1}$, A. G. ANDRADE ${ }^{2}$, J. I. H. T. NETO ${ }^{3}$, \\ J. I. SOLETTI ${ }^{4}$, S. H. V. CARVALHO \\ ${ }^{1}$ Bolsista de Iniciação científica UFAL; ${ }^{2}$ Mestre UFAL; ${ }^{3}$ Braskem; ${ }^{4}$ Docente UFAL \\ CTEC/UFAL - Universidade Federal de Alagoas \\ e-mail: rafaella.luna89@gmail.com
}

\begin{abstract}
RESUMO - O hipoclorito de sódio é um composto químico fotossensível, de fácil decomposição e oxidação, obtido através da reação do cloro com uma solução de hidróxido de sódio. O comércio deste é favorecido devido a sua grande utilização em tratamento de água, atividades odontológicas e uso hospitalar. Por ser um produto facilmente degradável, é necessário o entendimento dos fatores que levam a sua decomposição durante o manuseio, estocagem e transporte do mesmo. Fatores como temperatura e contaminantes metálicos, como níquel, presentes nos tanques e tubulações industriais, favorecem o aumento da velocidade de decomposição do hipoclorito afetando assim, a especificação do produto final. O objetivo deste trabalho é avaliar a influência da temperatura e da concentração do níquel na degradação do hipoclorito, visando uma melhor qualidade do produto. Os experimentos foram realizados a temperaturas de 20 e $30^{\circ} \mathrm{C}$, considerando uma contaminação de $0,1,5,3,4,5$ e 6 ppm de níquel. A degradação do hipoclorito foi avaliada em função do tempo de meia vida, o qual é determinado pelo decaimento da concentração do cloro ativo. As análises foram realizadas periodicamente até a obtenção do tempo de meia-vida ou até que a concentração do cloro ativo estivesse abaixo de 10 ppm.
\end{abstract}

Palavras chave: hipoclorito de sódio, degradação, cinética do hipoclorito

\section{INTRODUÇÃO}

O hipoclorito de sódio é um composto químico oxidante e fotossensível de uso muito difundido, usado em tratamento de água, atividades odontológicas, sendo preparado em laboratório e industrialmente pela reação do cloro com uma solução de hidróxido de sódio (PÉCORA, 1985).

$\mathrm{O}$ produto apresenta-se usualmente como solução aquosa alcalina, o que permite aumentar a sua conservação contra a decomposição e, consequentemente, o desprendimento do cloro (ABICLOR, 2010).

De coloração amarelada e odor característico, contém de $10-25 \%$ de hipoclorito de sódio $(\mathrm{NaClO})$. Industrialmente, é comercializado nessa forma, a granel, e transportado em carros-tanques. O hipoclorito de sódio possui propriedades oxidantes, branqueantes e desinfetantes, servindo para inúmeras aplicações, tais como branqueamento 
da polpa de celulose e têxteis, desinfecção de água potável, tratamento de efluentes industriais, lavagem de frutas e legumes, além de participar como intermediário na produção de diversos produtos químicos (ABICLOR, 2010).

Um dos problemas enfrentado pelas indústrias produtoras de hipoclorito é a ampliação do mercado consumidor, limitado pela distância, devido à degradação do produto. $\mathrm{O}$ desconhecimento do comportamento da cinética de degradação do hipoclorito, o mau manuseio, como por exemplo, diluição ou armazenamento em tanques de estocagem de metal, fazem com que os produtos cheguem até seus clientes fora de especificação (concentração mínima de 8 $\mathrm{g} / \mathrm{L}$ de $\mathrm{NaOH}$ e $110 \mathrm{~g} / \mathrm{L}$ de $\mathrm{Cl}_{2}$ na solução) (BRASKEM, 2004), tornando inviável a sua comercialização.

Fatores como temperatura, luminosidade e contaminantes metálicos, principalmente $\mathrm{Ni}$, presentes nas tubulações e tanques industriais, afetam diretamente a velocidade de decomposição do hipoclorito (KING, 1996). O conhecimento dessa dinâmica poderá reverter essa situação se possibilitar a venda de hipoclorito de sódio para mercados mais distantes.

Com isso, o objetivo deste trabalho foi avaliar a cinética de degradação do hipoclorito de sódio na presença de $\mathrm{Ni}$ para as temperaturas de 20 e $30^{\circ} \mathrm{C}$, e avaliar as condições de transporte e armazenamento.

\section{METODOLOGIA}

Foi realizado um planejamento com um intervalo de 0 a $6 \mathrm{mg} / \mathrm{L}$ de adição de níquel, variando $1,5 \mathrm{mg} / \mathrm{L}$, em temperaturas de $20 \mathrm{e}$ $30^{\circ} \mathrm{C}$, em um tempo total de 84 dias de análise. Com isso, foram obtidas 10 amostras (Experimento 1 - de 1 a 5 com temperatura de $20^{\circ} \mathrm{C}$ e Experimento 2 - de 6 a 10 com temperatura de $30^{\circ} \mathrm{C}$ ).

A produção do hipoclorito de sódio deuse início em sua área industrial. $\mathrm{O}$ material feito foi dividido em garrafas âmbar com capacidade para $1 \mathrm{~L}$ de solução e foram feitas suas contaminações com cloreto de níquel de acordo com o planejamento. As garrafas foram acondicionados em banhos, de diferentes temperaturas $\left(20^{\circ} \mathrm{C}\right.$ e $\left.30^{\circ} \mathrm{C}\right)$, com tampa, para evitar a presença de luminosidade no experimento.

Portanto, para análise foram transferidos $5 \mathrm{~mL}$ da amostra para um balão volumétrico de $100 \mathrm{~mL}$, o qual foi avolumado com água deionizada. Em um erlenmeyer de $250 \mathrm{~mL}$, contendo $30 \mathrm{~mL}$ de uma solução de iodeto de potássio a $5,0 \%$, foram adicionados $10 \mathrm{~mL}$ da solução de hipoclorito diluída, tomando-se o cuidado de emergir a ponta da pipeta na solução de iodeto de potássio. Foram acrescentados $10 \mathrm{~mL}$ de ácido acético glacial, sendo imediatamente iniciada a titulação com uma solução de tiossulfato de sódio $0,1 \mathrm{~N}$, até obtenção de uma coloração amarelo-clara. Foi adicionado $1 \mathrm{~mL}$ de amido 0,5\%, prosseguindo com a titulação até o desaparecimento da coloração azul, quando, então, foi obtido o volume da solução de tiossulfato de sódio.

As análises foram feitas periodicamente até que a concentração de cloro ativo estivesse abaixo de $10 \mathrm{~g} / \mathrm{L}$ ou até que seus tempos de meia-vida fossem atingidos. Para determinação de cloro ativo foi utilizada a Equação 1:

$\left[\mathrm{Cl}_{2}\right]=35,46 \mathrm{~V} * N / v a * f d$

onde $\left[\mathrm{Cl}_{2}\right]$ é a concentração de cloro ativo na solução $(\mathrm{g} / \mathrm{L}), V$ é o volume gasto da solução de tiossulfato de sódio $(\mathrm{mL}), \quad N$ é a normalidade da solução de tiossulfato de sódio, va é o volume de amostra $(10 \mathrm{~mL})$ e $f d$ é o fator de diluição $(5 \mathrm{~mL} / 100 \mathrm{~mL}=0,05)$.

A concentração do hipoclorito é determinada através da concentração de cloro ativo contido na solução, e esta concentração foi determinada por titulometria, baseada na norma NBR 9425 /05. A concentração do hipoclorito pode ser expressa em (g/L), Equação 2:

$[\mathrm{NaClO}](\mathrm{g} / \mathrm{L})=1,05\left[\mathrm{Cl}_{2}\right]$

onde a constante 1,05 foi obtida pela razão entre o peso molecular do $\mathrm{NaClO}(74,5 \mathrm{~g} / \mathrm{mol})$ e do $C l_{2}(71 \mathrm{~g} / \mathrm{L})$. 


\section{RESULTADOS E DISCUSSÕES}

O experimento 1 verificou a influência da concentração de níquel para a degradação do hipoclorito de sódio, a $20^{\circ} \mathrm{C}$. Para o experimento 2 as condições das amostras foram mantidas, alterando-se apenas a temperatura para $30^{\circ} \mathrm{C}$.

Nas Tabelas 1 e 2 são apresentados os resultados dos experimentos 1 e 2, respectivamente.

Tabela 1: Decomposição do hipoclorito de sódio no experimento 1

\begin{tabular}{|c|c|c|c|c|c|}
\hline Amostra & 1 & 2 & 3 & 4 & 5 \\
\hline Níquel & $0 \mathrm{ppm}$ & $1,5 \mathrm{ppm}$ & $3 \mathrm{ppm}$ & $4,5 \mathrm{ppm}$ & $6 \mathrm{ppm}$ \\
\hline Temp. & $20{ }^{\circ} \mathrm{C}$ & $20^{\circ} \mathrm{C}$ & $20^{\circ} \mathrm{C}$ & $20^{\circ} \mathrm{C}$ & $20^{\circ} \mathrm{C}$ \\
\hline 0 Dias & 107,1 & 107,1 & 107,1 & 107,1 & 107,1 \\
\hline 28 Dias & 104,7 & 31,59 & 11 & 8,16 & 6,14 \\
\hline 42 Dias & 93,44 & 21,63 & 4,08 & 2,66 & 1,42 \\
\hline 56 Dias & 89,36 & 13,47 & 2,13 & 1,42 & 0,67 \\
\hline 70 Dias & 84,04 & 9,22 & 0,85 & 0,71 & 0,64 \\
\hline 84 Dias & 81,56 & 8,51 & 0,67 & 0,66 & 0,64 \\
\hline
\end{tabular}

Tabela 2: Decomposição do hipoclorito de sódio no experimento 2

\begin{tabular}{|c|c|c|c|c|c|}
\hline Amostra & 6 & 7 & 8 & 9 & 10 \\
\hline Níquel & $0 \mathrm{ppm}$ & $1,5 \mathrm{ppm}$ & $3 \mathrm{ppm}$ & $4,5 \mathrm{ppm}$ & $6 \mathrm{ppm}$ \\
\hline Temp. & $30^{\circ} \mathrm{C}$ & $30^{\circ} \mathrm{C}$ & $30^{\circ} \mathrm{C}$ & $30^{\circ} \mathrm{C}$ & $30^{\circ} \mathrm{C}$ \\
\hline 0 Dias & 107,1 & 107,1 & 107,1 & 107,1 & 107,1 \\
\hline 28 Dias & 97,46 & 25,69 & 8,47 & 7,98 & 5,19 \\
\hline 42 Dias & 88,6 & 0,71 & 0,71 & 0,71 & 0,71 \\
\hline 56 Dias & 79,9 & 0,67 & 0,63 & 0,65 & 0,66 \\
\hline 70 Dias & 76,1 & 0,64 & 0,58 & 0,57 & 0,57 \\
\hline 84 Dias & 74,47 & 0,6 & 0,57 & 0,55 & 0,52 \\
\hline
\end{tabular}

A partir dos dados apresentados nas Tabelas 1 e 2, uma representação gráfica foi gerada e apresentada na Figura 1.

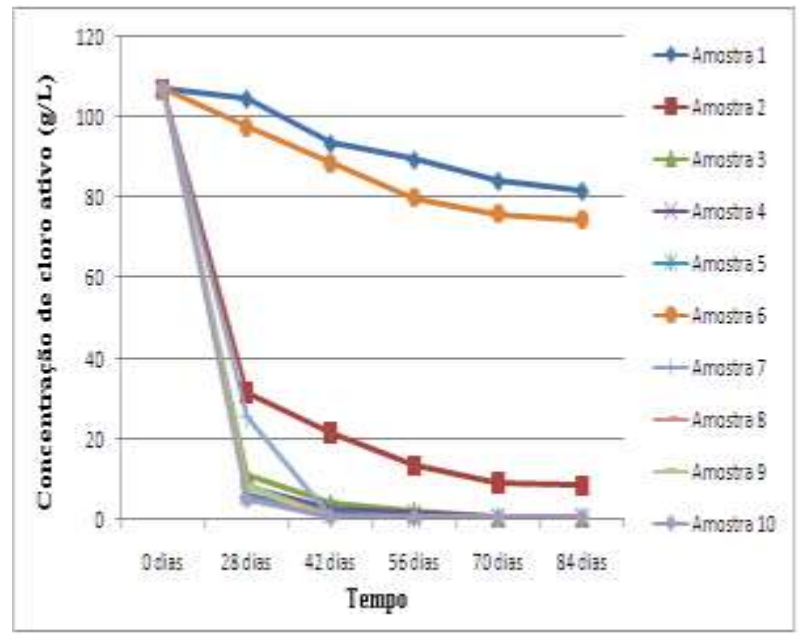

Figura 1: Concentração de cloro ativo em função do tempo
É possível perceber que o aumento da temperatura e da concentração do contaminante níquel, aumenta a velocidade de degradação do hipoclorito, diminuindo assim seu tempo de meia-vida.

Em relação à temperatura, compara-se as amostras 1 e 6 que possuem temperaturas diferentes e concentrações de níquel iguais, e percebe-se que a amostra 6 possui uma concentração de cloro ativo sempre abaixo da amostra 1 durante todo o tempo do experimento.

Em relação à concentração de níquel, compara-se as amostras 1 e 2 que possuem temperaturas iguais e concentrações de níquel diferentes, e percebe-se que a amostra 2 teve uma queda muito grande, da concentração de cloro ativo, durante os 28 primeiros dias, continuando o seu decaimento e sempre possuindo uma concentração de cloro ativo muito abaixo da amostra 1 .

Percebe-se que a partir dos 70 dias, a concentração de cloro ativo em cada amostra tende a ser constante e em sua maioria abaixo de $10 \mathrm{~g} / \mathrm{L}$.

\section{CONCLUSÕES}

Para as velocidades da reação foi percebido que seus valores se elevam com o aumento da temperatura e acréscimo de níquel, ou seja, eles realmente funcionam como catalisadores dessa reação, fato que não é interessante para o produtor e nem pra $\mathrm{o}$ consumidor.

Comparando-se os efeitos associados entre níquel e temperatura, conclui-se que o aumento de níquel, associado a temperatura, potencializam a degradação de hipoclorito de sódio, logo o tempo de meia-vida do hipoclorito se reduz mais rapidamente. Esses fatos levam a crer que temperatura mais baixa e a ausência de contaminantes irão deixar o hipoclorito de sódio com tempo de vida útil mais longo.

\section{REFERÊNCIAS}

ABICLOR, Relatório Anual 2010. Associação Brasileira da Indústria de Álcalis, Cloro e Derivados.

Disponível 
<http://www.abiclor.com.br> Acesso em 05/03/2012, 2010.

ABNT - Associação Brasileira de Normas Técnicas. NBR 9425:2005. Determinação do teor de cloro ativo pelo método volumétrico em soluções de hipoclorito de sódio comercial, 2005.

BRASKEM S. A., Folha de Dados de Hipoclorito de Sódio, n. 1, Rev. 4, 2004.

KING, F.; HANCOCK, F.E. Catalysis and pollution abatement: the removal of hypochlorite from waste chlorine/caustic effluent, Catalysis Today 27 (1996) 203207.

PÉCORA, J.D. Contribuição ao estudo da permeabilidade dentinária radicular. Apresentação de um método histoquímico e análise morfométrica. Ribeirão Preto, 1985. p. 110.(tese mestrado Faculdade de Odontologia USP).

\section{AGRADECIMENTOS}

Agradecemos ao Laboratório de Sistema de Separação e Otimização de Processos (LASSOP), a BRASKEM e a FUNDEPES. 